\title{
The Perceived Effects/Impacts of Auditory Deficiency on the Social and Academic Behavior of Students in Hail, Saudi Arabia
}

\author{
Maha Al-shammari, Asma Ashankyty, Najmah Al-Mowina, Nadia Al-Mutairy, Lulwah Al-shammari, Anfal al-qrnas, \\ Susan Amin ${ }^{*}$ \\ College of Medicine, University of Hail, Saudi Arabia \\ *Corresponding author: s.amin@uoh.edu.sa
}

Received January 07, 2014; Revised January 24, 2014; Accepted February 08, 2014

\begin{abstract}
Background: Studies of teachers' perceptions of students that are deaf and hard of hearing (SDHH) academic status compared with peers in high school mainstream and private classrooms are few, thus little is known of how SDHH fare in these classrooms. Current data on academic progress, especially prospective cross sectional data, are scant especially for the Kingdom of Saudi Arabia .Most of the studies that have been written for hearing loss have been based on younger children in the kingdom. The studies on students who are between the ages of 1518 and who are female are insufficient. We chose to look at both standardized surveys of both students' perceptions and teachers' perceptions to provide a multidimensional picture of the academic status of the SDHH in this study. In the following sections we: (a) Describe a framework for measuring academic status for students in Saudi Arabia; (b) Review the academic status of SDHH student; (c) Review the factors contributing to SDHH academic status. Methods: A cross sectional study was carried out on a hundred boys and girls of ages 15-18 with varying degrees of sensorineural deafness. This was carried out by interviews of the students and teachers, to answer our objectives. Results and Discussion: We were able to get a lot of gender specific information comparing female and male responses in Hail. In comparison with boys, girls on average felt they were treated significantly more differently by their parents (24 versus 10). Both girls and boys significantly on average felt that their academic performance was affected by their hearing loss (26 versus 25). Conclusion: This data has aided our understanding of the role of deafness and how it can impact academic performance in Hail. Integrated education in the future is something that would help the students with their communication and learning. Academic performance in Hail appears to be affected by interplay of a number of factors, pinpointing an exact factor would be of interest to future studies.
\end{abstract}

Keywords: deafness, hearing loss, academic performance, integration

Cite This Article: Maha Al-shammari, Asma Ashankyty, Najmah Al-Mowina, Nadia Al-Mutairy, Lulwah Alshammari, Anfal al-qrnas, and Susan Amin, "The Perceived Effects/Impacts of Auditory Deficiency on the Social and Academic Behavior of Students in Hail, Saudi Arabia." American Journal of Educational Research, vol. 2, no. 1 (2014): 54-65. doi: 10.12691/education-2-1-10.

\section{Introduction}

This paper explores the perspectives of deaf children and their teachers on school related issues, both academic and social in Hail, Saudi Arabia.

The term "hearing loss" in the medical and social senses has served to mean "an impairment of hearing". When a sound has to be increased in intensity for a person to hear it [1]. Types of hearing loss (HL) can be categorized by site of the auditory system damaged. There are three basic types of hearing impairment (HI): 1) conductive HI involving an impairment in conduction of sound from the outer ear to the middle ear ossicles, 2) sensorineural HI, occurs as a result of damage to the inner ear (cochlea) or nerve pathways from the inner ear to the brain, 3) mixed HI, involving the outer, middle and the inner ear [2].
Sensorineuronal deafness is more common in Saudi Arabia than in any other developing or developed region. Heredofamilial factors has been cited as the most common etiology [3].

Information is known about the impact of deafness on academic being in the western world. However the information is much limited on the results in the Middle East. The number of students who are deaf and hard of hearing $(\mathrm{SDHH})$ enrolled in higher education programs is far greater than those who are severely deaf and in some countries including Saudi Arabia students who are severely deaf are not enrolled in these programs with the attitudes being they are not capable of completing a degree [4].

Education models used to serve deaf students have evolved gradually over the last century. Early efforts have included private schools, some with instruction in sign language. This accounts for $38 \%$ of where SDHH receive 
their education. More recent models have focused on mainstreaming into general education classrooms with limited special services where $42 \%$ of the students receive their education or including special units in Private schools [5].

The other $17 \%$ of students receive education that is split between the special education and the generaleducation classroom [6].

Research on the academic achievement of $\mathrm{SDHH}$ indicates that they lag far behind what is expected of their hearing peers at similar ages or grade levels in the western world $[7,8]$. SDHH and receive their instruction in general education classrooms are reported to have higher academic achievement than those who receive instruction in self-contained classrooms $[9,10]$.

Academic status can be measured through several frames of reference: normative academic status, classroom academic status and academic progress. Normative academic status refers to students' standing compared with national or state norms and can be obtained through scores on national or state standardized academic achievement tests. Classroom academic status refers to students' achievement in comparison with classmates. Classroom status can be measured by obtaining teachers' perceptions of students' achievement and ability to learn expected academic content. Academic progress refers to the changes in the academic abilities of the students on a yearly basis [11].

Variables that can enhance or depress academic achievement such as degree of hearing loss, ethnicity, and socioeconomic status; family variables including parental support, resources and classroom and kind of special education support, have been examined by several researchers [12,13,14].

Based on a number of studies and an understanding of the disease conditions causing deafness, it is apparent that many of the causes of profound hearing loss are also responsible for impairments of neurological nature which commonly result in lower intelligence [15]. However, averages can mask the wide range of achievement of SDHH [13].

Early studies found that a higher degree of hearing loss was associated with lower academic achievement $[8,16,17]$ however, some recent research indicates that degree of hearing loss is not strongly associated with academic success [14]. Hearing thresholds in another study were also not related to composite reading and mathematics scores [18].

Minority ethnic status, usually associated with a home language different from the majority language, consistently depresses academic achievement $[8,14]$. This is of importance when assessing the academic achievement perceptions of SDHH in Saudi Arabia where the main language used in schools and homes is Arabic.

Variables that have been identified by researchers as contributing to the success of these students were good family support, student determination to succeed, and an outgoing personality [12].

Disassociating the influence of these variables is difficult because they are often connected in complex ways. Also, the variables are likely to be correlated to each other. For example, degree of hearing loss is likely to be related to receptive and expressive oral communication skills, which in turn may be related to communication and participation in the classroom.

Classroom participation for SDHH requires the ability of them to communicate with their teachers and other students. This is major requisite to academic success.

Social integration can be defined as the ability to interact with, make friends with, and be accepted by peers. In other words students need to be engaged in social activates to develop secure relationships with peers. Students who are not integrated may have feelings of loneliness, because they feel they cannot participate in activities because of their communication difficulties. ${ }^{19}$ They tend to be quiet as a result both inside and outside the classroom, this in turn will affect their academic performance [20].

Most (2006) compared teachers' perceptions of 33 Israeli-Arab SDHH and 66 hearing students in the same general education classrooms. A questionnaire that tapped the general education teachers' perception of student performance in five domains: academics, attention, communication, class participation, and school behavior was used. The teachers gave the SDHH significantly lower scores in all domains compared to their hearing peers [21].

One longitudinal study that tracked the achievement of SDHH in public high schools from 9th through $12^{\text {th }}$ grade, reported that students who had comparatively high achievement early in high school continued to achieve at a higher level at later grades [10].

Another longitudinal study reported on average, just less than $25 \%$ of SDHH achieved at grade level on the test of mathematics problem solving. The same students were also 3.6 grades below grade level on tests of reading and 3.0 grades below grade level on tests of mathematics at the time of their most recent assessment [22].

In comparison, a cross sectional study at a similar time to this study showed just less than $10 \%$ of $\mathrm{SDHH}$ achieved at grade level on the test of mathematics problem solving.

In other words, the achievement gap between SDHH and the general population has remained large and unchanged for many decades [23].

Another important historical perspective on the academic achievements of SDHH can be obtained by examining the two national longitudinal transition studies of special education students moving from their high school years to other paths. These studies allow direct comparison among the groups of students identified by their disability categories. On comparisons, of academic performance these investigators found that "students with visual or hearing impairments tended to have the best grades overall, as well as among the largest increases over time in receiving mostly A's”among students with disabilities as measured by achievement testing (especially tests of mathematics), high school completion, and attendance at postsecondary educational institutions [21,24,25,26,27].

One study on a co enrollment program for SDHH and normal hearing students in the USA found during academic activities grouping the two sets of students together resulted in increased interaction between these two groups of students. Stanford Achievement Test scores in the areas of reading vocabulary, reading comprehension, mathematical problem solving and procedures indicate 
that although SDHH scored below the national normative hearing group, reading comprehension levels exceeded the national normative sample of SDHH during both years two and three of the program [28].

A more current US study on academic progress of $\mathrm{SDHH}$ and hearing students in the general education classroom, found that $79 \%-81 \%$ of students made one or more year's progress annually. The teacher's ratings in this study also

Indicated that $89 \%$ of students made average or above average progress over five years [29].

Accommodations are in place in a number of deaf classrooms and are meant to make it easier for students with disabilities to gain access to test material without changing the difficulty of the item [30]. SDHH participate in state standardized assessments, with a significant proportion using at least one accommodation [31,32]. Accommodations in use in many parts of the western world include: Extended time this increases the time available to complete the exam. Another type of accommodation is small-group testing, when students complete the test in smaller groups instead of in the larger class. Both these accommodations are assumed not to significantly alter the content of the test [33,34,35].

Other accommodations make the test more accessible by changing the test direction or test item presentation, often times involving an "access assistant" for test administration [36]. An accommodation often used for $\mathrm{SDHH}$ is to have the test directions interpreted (TDI) into signed language, often with an access assistant such as an interpreter [33].

In the test item read aloud (TIR) accommodation, the student does not read the question, but listens to it read aloud by a teacher or other test administrator. A related accommodation is to have the test item interpreted (TII) for the student. For SDHH, test items may be translated into signed language used in instruction. This can be administered either in person or via a prerecorded, DVD format [37].

Cross sectional data and longitudinal studies of teachers' perceptions of SDHH' academic status compared with peers in high school mainstream and private classrooms are few, thus little is known of how $\mathrm{SDHH}$ fare in these classrooms especially for the Kingdom of Saudi Arabia. Most of the studies that have been written for hearing loss have been based on younger children in the kingdom. The studies on students who are between the ages of 15-18 and who are female are insufficient.

We chose to look at both standardized surveys of students' perceptions and teachers' perceptions to provide a multidimensional picture of the academic status of the SDHH in this study. In the following sections we

(a) Describe a framework for measuring academic status for students in Saudi Arabia

(b) Review the academic status of SDHH students by their perceptions, and

(c) Review the factors contributing to SDHH academic status.

\section{Methodology}

\subsection{Subjects}

A cross sectional study of 47 girls $(n=47)$ and 53 boys $(n=53)$ ( total $n=100$ ) with impaired hearing levels from a boy's and girl's deaf high school in Hail, Saudi Arabia were interviewed and surveyed by the participating student researchers. These students were randomly selected.

SDHH were eligible to participate if they met the following requirements at the time of enrollment in the study: (a) had an identified bilateral or unilateral hearing loss, (b) did not have additional severe cognitive disabilities, (c) received direct or consultative services from teachers of SDHH, (d) attended general or private education classrooms in public schools for two or more hours each day, and (e) were aged between 15-18 at the beginning of the study.

Due to the potentially sensitive nature of the views shared in the study, participants were not required to provide identifying information to participate in the survey. Responses were therefore anonymous unless individuals chose to provide their contact information.

The type of hearing loss of the students was sensorineural. The questions in the survey were designed to collect information on the aims for the project and to give us some information on deafness in Saudi Arabia. This age range was selected as a result of being under represented in other studies.

An aged match sample of normal hearing students were also surveyed with questions from our surveys at a similar time.

\subsection{Interviews}

The questionnaires used were in Arabic. The data collected from the questionnaires were translated into English. All interviews were conducted by the research students in the project. Most interviews were conducted in person to try and build a rapport with the student; the interviewer traveled to each school to meet with each interviewee. Typically, all interviews for a particular student were conducted in 2 days. Each SDHH teacher was also interviewed. Each interview required approximately $45 \mathrm{~min}$ to complete, although some were longer. Each interviewee was free to refuse to answer questions at their discretion.

\subsection{Ethical Approval}

The study protocol was approved by the research committee at the University of Hail and from the respective high schools. In addition, all the schools and students consented to involvement in the study.

\subsection{Methods and Academic Research Design}

Questionnaires tapping student's perceptions of academic functioning and academically-related social functioning included 29 items. Questions were based on items in the Academic Self-Description Questionnaire I (ASDQ-I [38]; and the Self-Description Questionnaires IIII $[39,40]$.

The Academic Competence scale of social skills rating that yield scores in three domains: social skills, problem behaviors, and academic competence [41]. Their classroom academic status was measured through teachers' perceptions of students' academic functioning 
using an adapted survey [22,42]. Teachers rate students on overall academic performance, motivation, intellectual functioning, classroom behavior, and parental encouragement.

The original forms of these instruments were not used because they included too many items given the time demands of the primary study, lacked items tapping some of the issues we wished to investigate, and had others superfluous to our needs. In addition, although the questions could be read verbatim to the students in the high schools by their teacher sign language versions in Arabic sign were needed by a majority of students.

All questions required responses on a 5-point scale representing true, mostly true, sometimes true/sometimes false, mostly false, and false. The teacher survey for accommodations in use to make teaching easier was measured by a 5 point scale where 1 meaning being difficult to implement and not in place and 5 being easiest to implement and in place [36].

The Appendix presents the major questions for each group of interviewees and the interview questions. We developed follow-up questions for each major question to obtain further information when necessary. Impaired hearing sections from the high schools were selected and a teacher from the school was used to help us in the translation of Arabic to sign language for the students.

\subsection{Demographic Status}

Demographic information on the students was collected through a form emailed to each student's teacher of SDHH who collected the data from the student's files, completed the form, and returned it to the researchers. The demographic data were used only to provide information on student characteristics; the academic data were used to determine the students' academic status.

\subsection{Statistical Analysis}

We used a Chi Squared test for the two groups of yes and no responses to test for differences in the male and female students to the questions in the survey. The level of significance in a chi-square for a two-tailed 1-df test was a value of 3.84 or greater. We used 2 way ANOVAs to test for interactions among gender, hearing status and academic performance of the students in this study. A p value of 0.05 or more was considered significant.

\section{Results}

Two groups of SDHH male and female from high schools in Hail, KSA of the same age group (15-18) were analyzed with questions in the survey to understand about deafness in Hail, KSA.

Demographics of the students

In comparison with females, more males significantly on average knew sign language (77\% versus 23\%) (Table $1)$. In comparison with males, more females significantly on average were fitted with hearing aids (83\% versus 17\%) (Table 1).

Table 1. Student demographic information for males and females collected for two high schools in Hail. Percentage change is given in parenthesis's as well as the numbers of actual students. * indicates significance $(\chi 2>3.84)$

\begin{tabular}{|l|l|l|l|}
\hline Characteristic & Total & Boys & Girls \\
\hline $\begin{array}{l}\text { Total number of } \\
\text { students }\end{array}$ & 100 & $53(53)$ & $47(47)$ \\
\hline Language at home: & 100 & $53(53)$ & $47(47)$ \\
\hline Arabic & 0 & 0 & 0 \\
\hline English & 100 & $15-17(53)$ & $15-17(47)$ \\
\hline Age & 35 & $6(17) *$ & $29 *(83)$ \\
\hline Mode of communication in school: \\
\hline Spoken with hearing aid & 31 & $24^{*}(77)$ & $9 *(23)$ \\
\hline Spoken and signed & 0 & 0 & 0 \\
\hline Signed & 100 & $53(53)$ & $47(47)$ \\
\hline Type of school: & 0 & 0 & 0 \\
\hline Private & 27 & $19 *(70)$ & $8 *(30)$ \\
\hline Mainstream & 27 & $8(30)$ & $19(70)$ \\
\hline Deaf since birth & 100 & $\begin{array}{l}\text { Missing } \\
\text { data }\end{array}$ & $\begin{array}{l}\text { Missing } \\
\text { data }\end{array}$ \\
\hline yes
\end{tabular}

Most of the male and female SDHH were educated in a private setting (Table 1).

In comparison with females, a greater number of males significantly on average were born deaf in this study (70\% versus 30\%) (Table 1).

All the students could understand Arabic both in the home and in the school and we were told by their teachers they could read lips and answer in some Arabic; however, their English ability was minimal.

The most prevalent form of communication is some type of sign and speech together by a single individual (83\%) followed by hearing aid (77\%). None of the students just used sign.

The students in this study did not answer questions relating to the socioeconomic impact. This section was therefore excluded from our study.

1. The Identification of the effects of deafness in the home.

Figure 1 was designed to answer questions on other factors relating deafness and the perceived effects of deafness in the home.

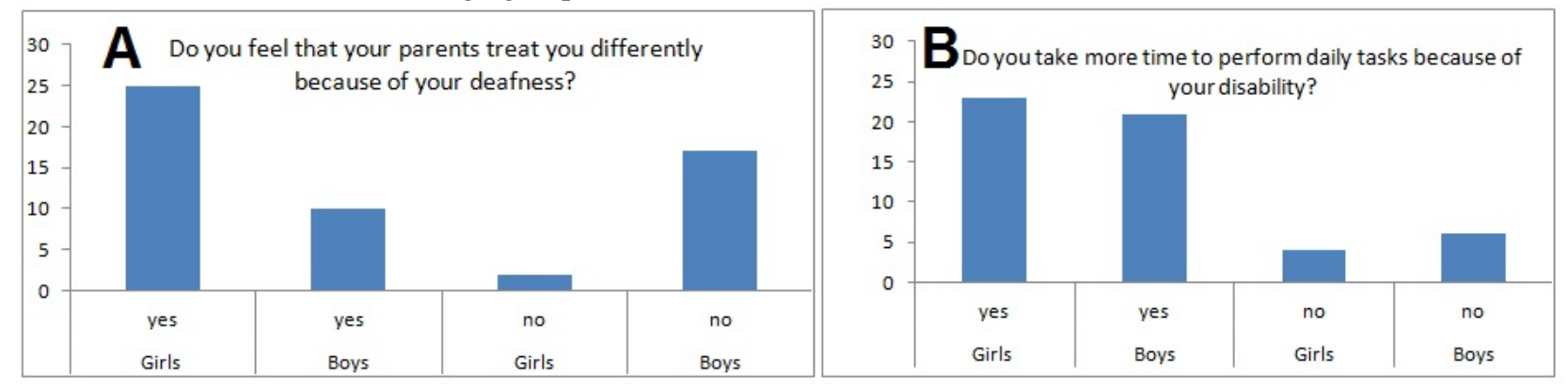

Figure 1. Responses to the questions by male and female SDHH: A) Do you feel that your parents treat you differently because of your deafness? B) Do you take more time to deal with daily tasks because of your deafness? The $\mathrm{X}$ axis is for gender and the $\mathrm{Y}$ axis is frequency of yes and no responses 
2. Responses on the academic performance of the deaf students

Figure 2 was designed to answer questions on the responses of the academic performances of the SDHH in relation to the home and outside the home .

In comparison with females, more males significantly on average $\left(\chi^{2}>3.84\right)$ had difficulty in communicating

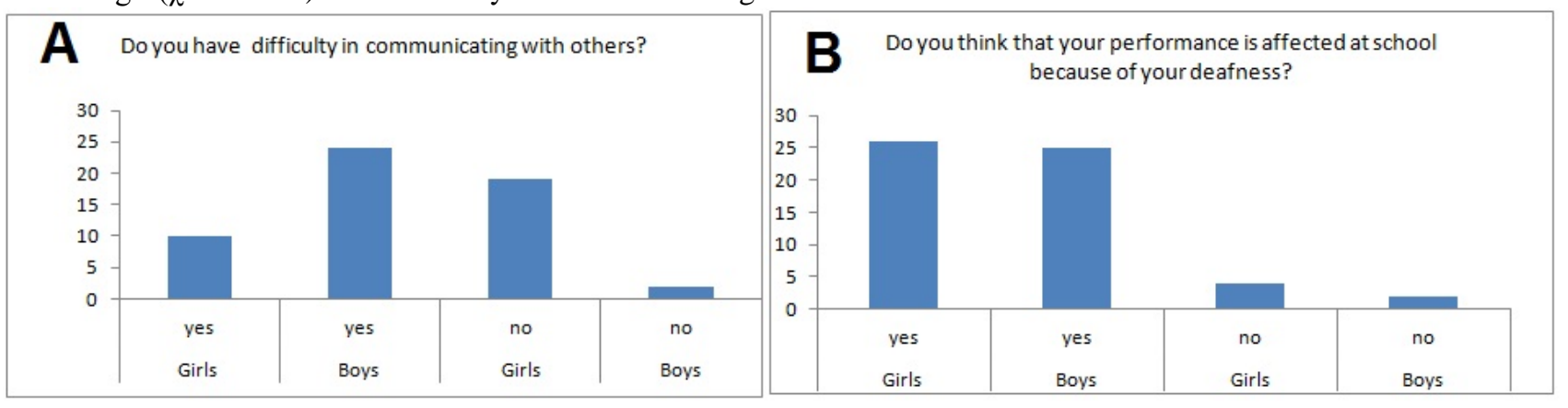

with others (hearing peers) in the school (26 versus 9) (Figure 2A).

Males and females significantly on average $\left(\chi^{2}>3.84\right)$ felt that their academic performance was affected by their deafness (26 versus 25) (Figure 2B).

Figure 2. Responses to the questions by male and female SDHH A) Do you face difficulty in communicating with others as in hearing peers ? B) Do you think that your performance is affected at school because of your deafness? The $\mathrm{X}$ axis is for gender and the $\mathrm{Y}$ axis is frequency of yes and no responses

Tables 2-4 were designed to answer our aims on the academic performance of the male and female SDHH. Most of the female SDHH preferred science as their

favorite and competent subject, whereas male $\mathrm{SDHH}$ preferred history (58\% versus 70\%) (Table 2).

Table 2. A comparison between male and female SDHH on their favorite competent subject at high school. * indicates significance $\left(\chi^{2}>3.84\right)$. Number of students is given and percentage from total is given in parenthesis's

\begin{tabular}{|c|c|c|c|c|c|c|c|}
\hline & $\begin{array}{c}\text { Favorite competent } \\
\text { subject at High school } \\
\text { Science }\end{array}$ & History & Geography & Geology & English & Math & Other \\
\hline Males difficulty in hearing & $6(30 \%)$ & $14(70 \%)$ & 0 & 0 & 0 & 0 & 0 \\
\hline Females difficulty in hearing & $20(58 \%)$ & $14(42 \%)$ & 0 & 0 & 0 & 0 & 0 \\
\hline
\end{tabular}

Table 3. A comparison between male and female SDHH on their performance level at school. $*$ indicates significance $\left(\chi^{2}>3.84\right)$. Number of students is given followed and percentage in parenthesis's

\begin{tabular}{|c|c|c|c|c|}
\hline Performance of the students & Below average & Average & Good & Excellent \\
\hline No of males with difficulty in hearing & 0 & 0 & $9 *(40 \%)$ & $14^{*}(60 \%)$ \\
\hline No of females with difficulty in hearing & 0 & 0 & $12^{*}(40 \%)$ & $18^{*}(60 \%)$ \\
\hline
\end{tabular}

Both the males and females SDHH in this study self more male SDHH significantly on average $\left(\chi^{2}>3.84\right)$ rated their academic performance in terms of performing in exams and classes as excellent. (60\%) (Table 3). In comparison with males, more female SDHH significantly on average $\left(\chi^{2}>3.84\right)$ agreed that businesses should provide special services for people with special needs (67\% versus 57\%) (Table 4). In comparison with females agreed that the university should provide sign language for all (66\% versus $17 \%$ ) (Table 4 ).

Tables 5-7 were designed to answer our aims on academic performance of the students in the school but use a normal hearing group as a comparison with SDHH.

Table 4. Comparison between males and female SDHH on the questions :Do you want to learn sign language at the university? , Do you think businesses should provide more facilities for special needed people? The rows give the number of yes and no responses and $*$ indicates value is significant $\left(\chi^{2}>3.84\right)$. No of students who answered is given as well as percentage from total in parentheses

\begin{tabular}{|c|c|c|}
\hline Do you want to learn sign language? & Yes & $24 *(66 \%)$ \\
\hline Number of males difficulty in hearing & $12 *(17 \%)$ & $12 *(34 \%)$ \\
\hline Number of females difficulty in hearing & No & $20 *(83 \%)$ \\
\hline Do you think businesses should provide more facilities for special needed people? & $12 *(57 \%)$ & No \\
\hline Number of males difficulty in hearing & $24 *(67 \%)$ & $9 *(43 \%)$ \\
\hline Number of females difficulty in hearing & $12 *(33 \%)$ & \\
\hline
\end{tabular}

Table 5. A comparison between hearing students and SDHH on their performance at school. * indicates significance $\left(\chi^{2}>3.84\right)$. Number of students is given as well as percentage from total in parenthesis's

\begin{tabular}{|c|c|c|c|c|}
\hline Performance of students & Below average & Average & Good & Excellent \\
\hline No of hearing students & $2 *(5 \%)$ & $17 *(30 \%)$ & $15 *(26 \%)$ \\
\hline No of difficulty in hearing students & 0 & 0 & $22(39 \%)$ \\
\hline
\end{tabular}

Table 6. Comparison between hearing and SDHH students on their favorite and competent subject at high school. $*$ indicates significance $\left(\chi^{2}>\right.$ 3.84). Number of students is given as well as percentage from total in parenthesis's

\begin{tabular}{|c|c|c|c|c|c|c|c|}
\hline & $\begin{array}{c}\text { Favorite subject } \\
\text { Science }\end{array}$ & History & Geography & Geology & English & Math & Other \\
\hline No of hearing students & $6 *(7 \%)$ & $14 *(15 \%)$ & $15 *(16 \%)$ & $11 *(13 \%)$ & $18 *(22 \%)$ & $15 *(16 \%)$ & $10 *(11 \%)$ \\
\hline No of difficulty in hearing & $20 *(58 \%)$ & $14 *(42 \%)$ & 0 & 0 & 0 & 0 & 0 \\
\hline
\end{tabular}


There was a statistically significant difference between the SDHH and the hearing group of females in rating sciences as their competent subject (58\% versus $7 \%$ ) (Table 6).

There was a statistically significant difference between the hearing group and the female SDHH in rating English as their competent subject (22\% versus $0 \%$ ) (Table 6).

Sixteen percent of the hearing group in this study favored Math; however, none of the SDHH chose it (Table 6).

The hearing students and the SDHH surveyed in this study self rated their performance at school as mostly excellent ( 39\% versus 60\%) (Table 5).
A number of the hearing students felt their academic performance was average at school. However, none of the SDHH felt their performance was average or below average ( $5 \%$ versus 0 ) (Table 5 ).

In comparison with female SDHH, hearing girls significantly on average agreed that businesses should provide special services for people with special needs (90\% versus 67\%) (Table 7). In comparison with female $\mathrm{SDHH}$, hearing girls significantly on average agreed that the university should provide sign language for all $(65 \%$ versus 37\%) (Table 7).

Table 7. Comparison between hearing and SDHH on the Questions: Do you want to learn sign language? Do you think businesses should provide more facilities for special needed people? The rows give the number of yes and no responses and $*$ indicates value is significant $\left(\chi^{2}>\right.$ 3.84). No of students who answered is given as well as percentage from total in parentheses

\begin{tabular}{|c|c|c|}
\hline Do you want to learn sign language? & Yes \\
\hline No of hearing students & $34 *(65 \%)$ & $18 *(35 \%)$ \\
\hline No of difficulty in hearing students & $12 *(37 \%)$ & $20 *(63 \%)$ \\
\hline Do you think businesses should provide more facilities for special needed people? & Yes & No \\
\hline No of hearing students & $55^{*}(90 \%)$ & $24 *(67 \%)$ \\
\hline No of difficulty in hearing students & $12 *(33 \%)$ & \\
\hline
\end{tabular}

\section{Classroom assessment by teacher}

There were expectations that the SDHH would achieve a pass in his or her subjects at the end of the semester. There were also good relationships with the parents of the students to facilitate more education at home. The expectations for one student were described by the teacher of SDHH:

"She is a good student but often cannot perform the religious prayer and we sometimes have to stop our work so we can teach her how to pray".

The expectations of another student were noted:

"She comes from a wealthy family and this is indicated by her knowledge of sign language and her ability to communicate with others and ask me for help when needed. She is also less angry compared to some of her peers from not so wealthy families".

The principal of the school this student attended noted:

"She tends to be isolated just like her peers and does not like to mix with the other hearing children in the other sections of the school".

The teacher commented on the teaching of these students and their time management:

"Exams are put back a lot of the time as the student's time management skills are not good. If the exam is supposed to be at 9am we often don't start until 10am. They also fail to study independently and need a lot of time from me. Their understanding of certain topics is also a weakness, where they may tell me they understand but they don't. We often spend two or three classes a week going through the same material."

The SDHH teacher in our study was also surveyed on accommodations in place in the class to make teaching easier as well as accommodations she would like to see in the future. The seven accommodations listed in the survey were as follows: extra time to complete the test, Smallgroup/individual testing (SGI) environments, test item read aloud to the student (TIR), test directions Interpreted for the student (TDI), test items interpreted for the student (TII), students gave signed Responses (SSR) and the use of simplified English (SE). The only accommodations in place were the smaller class size, extra time in testing and some test items read aloud to the student these had the highest ratings by the teacher of 5,5 and 4 respectively. She felt the other accommodations would need more time to implement; hence these received the lowest ratings (Table 8).

Table 8. Accommodations perception by a teacher of SDHH in place at the high school. Likert scale for accommodations with range 1 to 5 , 5 being in place and in use and easy to implement and 1 being not in place and difficulty in implementing [37]

\begin{tabular}{|l|l|r|}
\hline \multicolumn{2}{l|}{ Accommodations definitions and ratings } & rating \\
\hline Accommodationa Definition & & 5 \\
\hline Extended time & Student is given additional time to & \\
\hline & complete the test. This may be & \\
\hline & time and a half, double time, or & \\
\hline Small-group & unlimited time. & \\
\hline or individual & Student is tested in a separate room & 5 \\
\hline administration & from the main classroom, either & \\
\hline Interpreter for & with a small group or individually. & \\
\hline directions & The directions portion of the & \\
\hline & assessment is presented to the & \\
\hline & student via sign language & \\
\hline & (or other version such as cued & \\
\hline Interpreter for & speech, signed English, etc.). & \\
\hline test items & The test questions/items are given & 1 \\
\hline & to the student in ASL (or other & \\
\hline & signed system such as cued & \\
\hline TIR & speech, signed English, etc.). & \\
\hline & The test questions/items are read & 4 \\
\hline Sign response & aloud to the student. & \\
\hline for a scribe & A scribe writes down the responses & 1 \\
\hline SE & a student gives in sign language. & \\
\hline & The test is rewritten so that the & 1 \\
\hline & directions and items use simplified & \\
\hline & vocabulary and sentence structure. & \\
\hline & & \\
\hline & & \\
\hline & &
\end{tabular}

A number of students were also repeating the same semester as they did not pass in the last.

One general education teacher commented on her interactions with a teacher of SDHH:

"We often meet to try and get our students to do some activities together; just recently I sent some of my students to learn sign language with them. There needs to be more activities to encourage this".

Most of the students had feelings of isolation which in turn affected their communication. Many of the teachers for SDHH in this study wanted to see mainstream 
education. They felt that this would be of benefit to the students.

4. Interactions among hearing and academic performance

Preliminary analyses for group comparisons on the three scales examined possible differences between an interaction between hearing, gender and academic performance using 2 (gender: male. versus female) by 2 (hearing status: hearing aid versus sign and speech) by 2 (performance: good versus excellent perspective) analyses of variance (ANOVAs) in which the last factor was within-subjects. None of those analyses revealed any main effects or interactions both among and within for gender, hearing and performance.

We also looked at an interaction between gender, hearing and competent subject. Again none of those analyses revealed any main effects or interactions both among and within for gender, hearing and competent subject $(\mathrm{p}<0.05)$.

\section{Discussion}

The following study was undertaken at high schools for males and female SDHH in Hail to look at the patterns of deafness among girls and boys in Saudi Arabia through the following:

(a) Describe a framework for measuring academic status for students in Saudi Arabia

(b) Review the academic status of SDHH students by their perceptions, and

(c) Review the factors contributing to SDHH academic status.

All the students in this study were educated in private sections; this may be as a result of the communication difficulties they may encounter and the fear of being stigmatized [43].

However, in many parts of the world there has been a shift towards integration of SDHH and normal hearing students. The teachers we surveyed actually preferred this in our survey. The much improved options of hearing aid fitting and cochlear implantation [44]. The programs available for newborn hearing screening have made this possible in the Western world, similar programs here could have the same effect [45].

Numerous studies have found higher levels of academic achievement among SDHH in mainstream classrooms than in schools for the deaf $[9,46]$. Kluwin described what he referred to as a "cumulative effect"' of mainstream placement, insofar as achievement was positively related to the number of classes taken in regular classrooms as well as their academic intensity [47].

Most of the boys in this study were actually deaf since birth compared to the girls (70\% to $30 \%$ ); this may be linked to most of the males in this study communicating by sign language. Girls on the other hand, had differing degrees sensorineuronal deafness and hence most of then used hearing aids. Hearing aids were easier for the girls as some found the sign language difficult and tended to be more isolated as a result. Sign language would be easier for the boys as they had fewer barriers when dealing with people and were less restricted compared to females. None of the students in this study used just sign it was mixed with speech. This coincides with another study that also found the most prevalent form of communication among SDHH students is some type of sign and speech together by a single individual (56\%) followed by sign language (45\%) and oral only (44\%) [48].

However, this contrasts results of a study in the US where teachers noted that more female students showed a stronger interest in sign language and developed sign skills more rapidly than male students. Friendships between SDHH and hearing students therefore first developed between female students [29].

The lack of interaction in our study between gender, hearing and performance coincide with those of another study who also found that gender did not interact with hearing status. Academic performance is affected by a number of interrelated factors as in our study [49].

We were able to get a lot of gender specific information comparing female and male responses. Males tended to favor subjects like History, Females tended to favor subjects like science. Both the males and females in our study rated their academic performance as excellent.

They both may feel their academic progress is excellent as they were doing well in the same material as the previous semester. This contrasts with one study that found gender differences showing higher scores of academic performance in females who were deaf [50].

Most of the hearing students in this study were truthful in their abilities at school, However most of the SDHH in this study said their performance was excellent and none of them reported average or below average performances, these overestimated performances are also in line with another study that found that students whose grade point average (GPA) placed them in lower ranges of performance overestimated their own academic performance and those whose GPA placed them in a higher range were more truthful with their performance [51].

The fact that lower performing students overestimated their performance academically and were generally satisfied with it suggests that lower performing deaf students do not have the metacognitive skills to accurately assess what they know and what they need to study [52].

More girls who were deaf felt they were treated differently by their parents in the home compared with the boys. This may be due to Saudi culture which aims to protect women from the outside world.

Many of the girls surveyed in our study like science In addition to field specific vocabulary, science tests can also include demonstrations of procedural knowledge [52]. Procedural knowledge tasks tend to have lower reading demand than factual knowledge and recall. Two of the most common ways to capture procedural knowledge are concept maps and laboratory demonstrations. This is in contrast to another study which found the complete opposite. On the performance scale of the WISC-R (the Wechsler Intelligence Scale for Children) deaf boys tend to perform at somewhat higher levels than deaf girls on subtests that are highly visual and spatial in nature (specifically, block design, object assembly, and picture completion). Deaf girls tended to outperform deaf boys on the coding subtest. Some psychologists think that the coding subtest, although nonverbal in nature, is related to language ability [53].

All of the SDHH in this study did not choose English or Math as subjects they were competent in as, compared to 
the normal hearing group. English is not their native language so could choose not to study it. English and Math were chosen as competent subjects by the normal hearing group indicating that our SDHH were behind their peers in these subjects. This is in line with other studies who also found the English and Math levels of SDHH to be behind that of their peers [51].

One study, reported more females than males as being deaf in one area of Saudi Arabia [54]. Deafness maybe gender specific in some regions of Saudi Arabia and may be due to there being more boys or girls residing or born in some regions of KSA as well as a hereditary component. This will be of interest for further studies.

Verbal communication skills, preparing for exams and understanding certain topics in class were a weakness in the class among the SDHH in our study. This coincides with one study that also found a similar weakness among SDHH using these parameters. Students who were assessed as having strengths in these areas obtained significantly higher GPAs than did those who were assessed as having weaknesses [51].

There were a high number of males and females who had difficulties in communicating in the school and home and found that their academic abilities were affected by their deafness, even though they rated their performance in classes as excellent. They may be okay in the school as they have a teacher, but may find it difficult at home when they are in isolation. This coincides with studies that found that deaf adolescents' perceptions of their ease of communication in the classroom were a significant predictor of achievement grades [19,30].

However, is in contrast to a study that found no differences in Stanford Achievement Test Mathematics and Computation scores between deaf students who relied on spoken language and those who relied on sign language interpreters in mainstream classrooms [9]. More recent studies, however, have indicated that experienced teachers of the deaf signing for themselves do not facilitate learning to any greater extent than when they use sign language interpreters, regardless of whether the teachers are hearing or deaf [55].

Other studies have shown that students who perceive classroom participation as satisfying have higher scores for quality of life in school, social contact with peers, and mental health [56].

In our study the teacher for SDHH informed us that many of the students she taught did not have deaf parents.

The parents of deaf children perhaps may not feel skilled enough to communicate with their deaf children [57]. One study suggests that mothers who can communicate better with their deaf child may also feel more at ease to interact with their child in settings other than the home [58].

A number of studies have shown a higher than average nonverbal IQ shown by deaf children raised in deaf families compared to those raised in non deaf families [59]. One hypothesis is that the performance difference reflects the fact that intelligence is, in part, inherited [59]. The second explanation emphasizes the impact of the child's early environment on cognitive development. Deaf parents are better prepared than hearing parents to meet the early learning needs of the deaf child by interacting with them in sign $[60,61]$.
Socioeconomic status may have a greater impact on the academic attainment of deaf children than that of hearing children. This is because hearing children, no matter how poor, can acquire language by merely listening to family members who speak to them from infancy. By contrast, poor deaf children are at a high risk for not being exposed to accessible language at the right time in early childhood [62]. Socioeconomic status is something we did include in the survey, but was not answered by our students. Different ways to ask about this could be introduced in further studies.

More help in high schools such as more interaction between parents and teachers could help as well as more deaf education workshops for parents.

A number of students in our cohort were repeating material for the semester again, Research has found that auditory experience does influence short term memory (STM) span but indirectly, not directly. Audition affects STM span because it plays a major role in spoken language acquisition. Deaf children vary widely in their level of language development (spoken or signed), familiarity with written words, and in whether and how they use mental rehearsal as a strategy to facilitate recall [63].

In our study a number of accommodations to make teaching easier by the teachers of SDHH were already in place such as smaller class size, 15 students were present in one class, extended time was given in all exams as well as test items read aloud. These accommodations were suggested as easy to implement. However, accommodations suggested by the teacher for future use include test items and test directions interpreted. These were considered by her as difficult to implement and would need more time. These perspectives of accommodations coincide with another study that found similar teacher perspectives [64].

Teachers of SDHH did report to us that students had difficulty understanding the questionnaire items. In terms of differences in the responses between the males and females, the males finished their surveys much quicker and with ease compared to the females who needed more time to understand the questions. However, we did not obtain data on how many students read the items independently. In future studies this can be a form of assessment.

Saudi cultural values deal with disabilities according to the policies included in the Quran These values often lead people in Saudi Arabia to treat individuals with disabilities negatively; for example, these individuals are not able to live independently and may be ignored in public [65].

In our study the teacher signed as well as verbally spoke to the students. In the interviews the students could answer and point at the same time. Their speech was not that impaired. This is in line with another study that found that early exposure to cued speech and phonetics for hearing impaired students could permit the development of linguistic skills necessary in order to learn reading and writing [66].

The teacher for SDHH in this study wanted to help the students in the classroom as much as possible yet felt worried for her students covering the same material again these beliefs are in line with another study that found high overall efficacy beliefs in instructional strategies and 
classroom management and significantly lower efficacy beliefs in the area of student engagement [67].

\section{Implications for Research}

One of the difficulties of a study of SDHH in the private schools is the issue of sample representativeness. In particular for KSA, there are a number of deaf students that are not registered with any system.

We did obtain data on a matched group of hearing classmates but this was only for females. Future researchers may want to include such a comparison group for males. Future studies could also look into to actual test scores of the students in all subjects as well as their abilities later in life to do a bachelors degree and go into the work place in a longitudinal study. As Around 30\% of deaf students graduate from 4-year programs compared to about $70 \%$ of their hearing peers [68].

These results are for a sample of students in one area of KSA, to get a better representation, a nationwide study could be a next focus of research.

We obtained responses from a female teacher for SDHH, but not a male, this may have affected the responses as, one study found that male teachers had more positive attitudes toward integration education for students with learning disabilities than female teachers [69]. Whereas another study found the complete opposite [70]. Future studies could obtain responses from both genders.

\section{Recommendations}

Barriers to understanding could be prevented by introducing sign language in a number of schools and universities.

Saudi society is becoming more accepting to these students with hearing loss; there are more government services available as well as entrance to universities in the KSA region.

There should be routine examinations done for newborn babies to detect for hearing deformities in KSA. This is a common practice in some parts of the western world [71].

More facilities should be available for SDHH and normal hearing students to interact, as well as more workshops in Hail to help us understand about deafness and its effects on society.

The development of audiological services in other school health centers in the country will help with better treatment outcomes [51].

More assistance to deaf students in their classes such as longer lesson periods, hearing students who know sign language to be buddies for them, more access to support services outside school, easy access to interpreters could aid in their transition from high school to university.

\section{Conclusions}

Perspectives of the teachers for SDHH and SDHH has been an invaluable tool in this study for assessing the social and academic performance in this study

For this group of SDHH, results show here that personal factors that are related can play a significant role in academic success and it is difficult to pinpoint exact factors.

Students' expressive and receptive communication, classroom participation, communication mode, and parental participation in school were related to academic outcomes.

The SDHH in this study lag behind their peers in subjects like English and Math, although test scores in future studies over time would be better able to confirm this.

\section{Conflicts of Interest}

There are no conflicts of interest in this study

\section{Authors Contributions}

MA wrote part of the paper and prepared a lot of the questions in the survey. AA and NM collected students, composed surveys and distributed surveys. NA provided all the data analysis. LA and AA translated surveys for the students into Arabic from English and vice versa as well as data analysis. SA wrote most of the paper and was the PI for the project.

\section{References}

[1] Davis H, Silverman SR. Hearing and Deafness, fourth edition, Holt, Rinehart and Winston. 1978; USA.

[2] Newby HA, Poplka GR. Audiology, Six Edition Englewood cliffs. 1992; New Jersey, Prentice- Hall Inc.

[3] El-Sayed Y, Zakzouk S. Prevalence and etiology of childhood sensorineural hearing loss (SNHL) in Riyadh. Ann Saudi Med. 1997; 17(4):487.

[4] Breljie HW, 1999 Post secondary opponent for deaf in HW Breljie (Eds) Global perspectives on education of the deaf in selected countries Hilsboro OR butte publication.

[5] Moores D. Educating the deaf, Houghton Mifflin. 1996; Boston.

[6] Holden-Pitt L, Diaz JA. Thirty years of the annual survey of deaf and hard-of-hearing children \& youth: A glance over the decades. American Annals of the Deaf. 1992; 142(2): 72-76.

[7] Traxler CB. Measuring up to performance standards in reading and mathematics: Achievement of selected deaf and hard-ofhearing students in the national norming of the 9th Edition Stanford Achievement Test. Journal of Deaf Studies and Deaf Education. 2000; 5: 337-348.

[8] Allen T. Patterns of academic achievement among hearing impaired students: 1974 and 1983. In A. Schildroth \& M. Karchmer (Eds.), Deaf children in America 1986 (pp.161-206). Boston: Little Brown.

[9] Holt J. Classroom attributes and achievement test scores for deaf and hard of hearing students. American Annals of the Deaf. 1994; 139, 430-437.

[10] Kluwin TN \& Stinson MS. Deaf students in local public high schools: Backgrounds, experiences, and outcomes.1993, Springfield, MA: Charles C. Thomas.

[11] Semmel MI \& Frick T. Learner competence in school In M Kaufman JA. Agard \& M I. Semmel (Eds.), Mainstreaming: Learners and their environment, 1985 (pp. 99-150) Cambridge: Brookline Books.

[12] Luckner JL, Muir S. Successful students who are deaf in general education settings. American Annals of the Deaf. 2001; 146:435445.

[13] Karchmer M, Mitchell RE. Demographic and achievement characteristics of deaf and hard-of-hearing students. In M. Marschark \& P. E. Spencer (Eds.), Oxford handbook of deaf studies, language, and education, New York: Oxford University Press, 2003: 21-37. 
[14] Power D, Hyde M. Itinerant teachers of the deaf and hard of hearing and their students in Australia: Some state comparisons. International Journal of Disability Development and Education. 2003; 4: 385-401.

[15] McCay V. 10th Anniversary Classics Fifty Years of Research on the Intelligence of Deaf and Hard-of-Hearing Children: A Review of Literature and Discussion of Implications. Journal of Deaf Studies and Deaf Education. 2005; 225-231.

[16] Davis JM, Shepard NT, Stelmachowicz PG \& Gorga M P. Characteristics of hearing-impaired children in the public schools: Psycho-educational data. Journal of Speech and Hearing Disorders. 1981; 46, 130-137.

[17] Wolk S \& Allen TE. A 5-year follow-up of readingcomprehension achievement of hearing-impaired students in special education programs. Journal of Special Education. 1984; 18, 161-176.

[18] Tymms P, Brien D, Merrell C, Collins J, Jones P. Young deaf children and the prediction of reading and mathematics. Journal of Early Childhood Research. 2003; 1:197-212.

[19] Long G, Stinson MS, Braeges J. Student's perception of communication ease and engagement: How they relate to academic success. American Annals of the deaf. 1991; 136:414421.

[20] Scheetz. Orientation to deafness, Needham Heights: Allyn and Bacon. 1993:86-90.

[21] Most T. Assessment of school functioning among Israeli Arab children with hearing loss in the primary grades. American Annals of the Deaf. 2006; 151:327-335.

[22] Wagner M, Marder C, Blackorby J, Cameto R, Newman L, Levine $\mathrm{P}$, et al. The achievements of youth with disabilities during secondary school. A report from the National Longitudinal Transition Study-2 (NLTS2).2003; Menlo Park, CA: SRI International. Office of Demographic Studies. (1969). Academic achievement test performance of hearing impaired students. Washington, DC: Gallaudet College.

[23] Gallaudet Research Institute. Stanford Achievement Test, 10th Edition, National Deaf and Hard of Hearing Student Norms Project, non-public data file. 2003, Washington, DC: Gallaudet Research Institute, Gallaudet University.

[24] Blackorby J \& Knokey IS. A national profile of students with hearing impairments in elementary and middle school: A special topic report from the Special Education Elementary Longitudinal Study. 2006, Menlo Park, CA: SRI International.

[25] Wagner M, Newman L, \& Cameto R. Changes over time in the secondary school programs of students with disabilities. A report of findings from the National Longitudinal Transition Study and the National Longitudinal Transition Study-2 (NLTS2). 2004, Menlo Park, CA: SRI International.

[26] Wagner M, Newman L, Cameto R, \& Levine P. Changes over time in the early post school outcomes of youth with disabilities. A report of findings from the National Longitudinal Transition Study (NLTS) and the National Longitudinal Transition Study-2 (NLTS2). 2005, Menlo Park, CA: SRI International.

[27] Wagner M, Newman L, Cameto R, \& Levine P. The academic achievement and functional performance of youth with disabilities. A report from the National Longitudinal Transition Study-2 (NLTS2). (NCSER 2006-3000). 2006, Menlo Park, CA: SRI International.

[28] Kreimeyer KH, Crooke P, Drye C, Egbert V, Klein B. Academic and Social Benefits of a Co-enrollment Model of Inclusive Education for Deaf and Hard-of-Hearing Children, Journal of Deaf Studies and Deaf Education 5:2 spring 2000, 174-185.

[29] Antia SD. Jones PB Reed S Kreimeyer KH, Academic Status and Progress of Deaf and Hard-of-Hearing Students in General Education Classrooms, Journal of Deaf Studies and Deaf Education 14:3 summer 2009.293-311.

[30] Lazarus S S, Thurlow M L, Lail K E, Eisenbraun K. D, \& Kato K. 2005 state policies on assessment participation and accommodations for students with disabilities (synthesis report 64). Minneapolis, MN: University of Minnesota, National Center on Educational Outcomes. Retrieved November 29, 2006, from http://education.umn.edu/NCEO/OnlinePubs/Synthesis64/

[31] Cawthon SW. Schools for the deaf and the No Child Left behind Act. American Annals of the Deaf. 2004 149, 314-323.

[32] Cawthon SW \& Online Research Lab. Findings from the National Survey on accommodations and alternate assessments for students who are deaf or hard of hearing. Journal of Deaf Studies and Deaf Education. 2006; 11, 337-359.
[33] Elliott SN, Braden JP. Educational assessment and accountability for all students: Facilitating meaningful participation of students with disabilities in district and statewide assessment programs. 2000, Madison: Wisconsin Department of Public Instruction.

[34] Phillips SE. High-stakes testing accommodations: Validity versus disabled rights. Applied Measurement in Education. 1994; 7(2); 93-120.

[35] Shriner JG, DeStefano L. Participation and accommodations in state assessment: The role of individualized education programs. Exceptional Children. 2003; 69(2); 147-161.

[36] Clapper A T, Morse A, Lazarus S S, Thompson S J, \& ThurlowM L. 2003 state policies on assessment participation and accommodations for students with disabilities (Synthesis Report 56). Minneapolis, MN: University of Minnesota National Center on Educational Outcomes 2005. Retrieved November 29, 2006, from http://education.umn.edu/NCEO/OnlinePubs/Synthesis56.html.

[37] Maihoff NA, Bosso E, Zhang L, Fischgrund J, Schulz J, Carlson J, et al. The effects of administering an ASL signed standardized test via DVD player/television and by paper and pencil: A pilot study. Report for the Delaware Department of Education, 2000. Retrieved September 5, 2006, from http://www.doe.k12.de.us/AAB/DSTP_research.html.

[38] Marsh HW. The structure of academic self-concept: The Marsh/Shavelson model. Journal of Educational Psychology. 1990; 82:623-636.

[39] Marsh HW. A test manual and research monograph. Macarthur, New South Wales, Australia: University of Western Sydney, Faculty of Education; 1992. Self Description Questionnaire (SDQ) II: A theoretical and empirical basis for the measurement of multiple dimensions of adolescent self-concept.

[40] Marsh HW, Shavelson RJ. Self-concept: Its multifaceted, hierarchical structure. Educational Psychologist. 1985; 20:107125.

[41] Gresham FM, \& Elliott SN. Social Skills Rating System. Circle Pines, MN: 1990; American Guidance Service.

[42] Powers S. Influences of student and family factors on academic outcomes of mainstream secondary school students. Journal of Deaf Studies and Deaf Education. 2003; 8:57-78.

[43] Antia SD. Can deaf and hard of hearing students are successful in general education classrooms? [Electronic Version]. Teachers College Record. Retrieved February 5, 2007, from http://www.tcrecord.org.

[44] Freire S. Creating inclusive learning environments: Difficulties and opportunities within the new political ethos. Journal of Deaf Studies and Deaf Education. 2009; 14: 131-135.

[45] National Center for Hearing Assessment and Management. State summary statistics: Universal newborn hearing screening. Retrieved September 17, 2009, from http://www.infanthearing.org/status/unhsstate.html.

[46] Kluwin T. Cumulative effects of mainstreaming on the achievement of deaf adolescents. Exceptional Children. 1993; 60; 73-81.

[47] Adelman, C. The toolbox revisited: Paths to degree completion from high school through college. 2006, Washington, DC: United States Department of Education.

[48] Cawthon SW, Science and Evidence of Success: Two Emerging Issues in Assessment Accommodations for Students Who Are Deaf or Hard of Hearing, Journal of Deaf Studies and Deaf Education 15:2 spring 2010; 185-203.

[49] Marschark M, Bull R, Sapere P, Nordmann E , W Skene W, Lukomski J , and Lumsden S. Do You See What I See? School Perspectives of Deaf Children, Hearing Children and Their Parents. Eur J Spec Needs Educ. 2012 September 1; 27(4): 483-497.

[50] Musselman C, Szanto G. The written performance of deaf adolescents: Patterns of performance. Journal of Deaf Studies and Deaf Education.1998; 3:245-257.

[51] Albertini JA, Kelly RR, Matchett $M K$, Personal Factors That Influence Deaf College Students' Academic Success. Journal of Deaf Studies and Deaf Education. 2011; 17 (1): 85-101.

[52] Patz R J. Building NCLB science assessments: Psychometric and practical considerations (Final Report submitted to the National Research Council Committee on Test Design for K-12 Science Achievement). 2005, Washington, DC: National Academy of Sciences.

[53] Phelps L, Ensor A. The comparison of performance by sex of deaf children on the WISC-R. Psychology in the Schools. 1987; 24; 209-214. 
[54] Al-Rowaily MA, AlFayez AI, AlJomiey MS, AlBadr AM, Abolfotouh MA. Hearing impairments among Saudi preschool children. Int J Pediatr Otorhinolaryngol. 2012; 76(11):1674-7.

[55] Marschark M, Sapere P, Convertino CM, \& Pelz J. Learning via direct and mediated instruction by deaf students. Journal of Deaf Studies and Deaf Education. 2008; 13; 546-561.

[56] Hintermar M. Health-Related Quality of Life and Classroom Participation of Deaf and Hard-of-Hearing Students in General Schools. Journal of Deaf Studies and Deaf Education. 16:2 spring 2011; 254-271.

[57] Powers GW, Saskiewicz JA. A comparison study of educational involvement of hearing parents of deaf and hearing children of elementary school age. American Annals of the Deaf. 1998; 143: 35-39.

[58] Calderon R. Parental Involvement in Deaf Children's Education Programs as a Predictor of Child's Language, Early Reading, and Social- Emotional Development. Journal of Deaf Studies and Deaf Education. 2000; 5:2: 140-155.

[59] Kusche CA, Greenberg MT, and Garfield TS: Nonverbal intelligence and verbal achievement in deaf adolescents: An examination of heredity and environment. American Annals of the Deaf. 1983; 127; 458-466.

[60] Schlesinger HS, Meadow KP: Sound and Sign: Childhood Deafness and Mental Health. Berkley: University of California Press, 1972.

[61] Sisco FH, Anderson RJ: Deaf children's performance on the WISC-R relative to hearing status of parents and child-rearing experiences. American Annals of the Deaf.1980: 923-930.

[62] Mayberry RI. CHAPTER 4 Cognitive developments in deaf children: the interface of Language and perception in neuropsychology. Handbook of Neuropsychology. 2nd Edition 2002, 8(2):71-107.
[63] Hoemann HW. Piagetian perspectives on research with deaf students. In Keating DP, Rosen H (Eds), Constructivist perspectives on developmental psychopathology and atypical development. Hillsdale, NJ: Erlbaum, 1991.

[64] Cawthon SW. Accommodations Use for Statewide Standardized Assessments: Prevalence and Recommendations for Students Who Are Deaf or Hard of Hearing, Journal of Deaf Studies and Deaf Education. Winter 2008; 13:1; 55-76.

[65] Alquraini T. Special Education in Saudi Arabia: Challenges, Perspectives, Future Possibilities, International. Journal of special Education. 2011; 26(2).

[66] Colin S, Leybaert J, Ecalle J, Magnan A, The development of word recognition, sentence Comprehension, word spelling, and vocabulary in children with deafness: A longitudinal study, Research in Developmental Disabilities. 2013; 34; 1781-1793.

[67] Garberoglio CL. Gobble ME, Cawthon SW, A National Perspective on Teachers' Efficacy Beliefs in Deaf Education. Journal of Deaf Studies and Deaf Education. June 2012; 17:3: 367-383.

[68] Marschark M, Lang H, \& Albertini J. Educating deaf students: From research to practice. New York, NY, 2002: Oxford University Press.

[69] Al-Ahmadi NA. Teachers' perspectives and attitudes towards integrating students with learning disabilities in regular Saudi public schools (Doctoral dissertation) Available from ProQuest Dissertations and Theses database 2009. (UMI NO. AAT 3371476)

[70] Al Abduljabber AM. Administrators' and teachers' perceptions of inclusive schooling in Saudi Arabia. Dissertation Abstracts International. 1994; 56(07): 9536504.

[71] Kennedy C. McCann D, Campbell MJ, Kimm L, Thornton R. Universal Newborn trial, screening for permanent childhood hearing impairment: an 8 year follow-up of a controlled. Lancet. 2005; 366 (9486):660-662.

\section{Appendix}

Student questionnaire

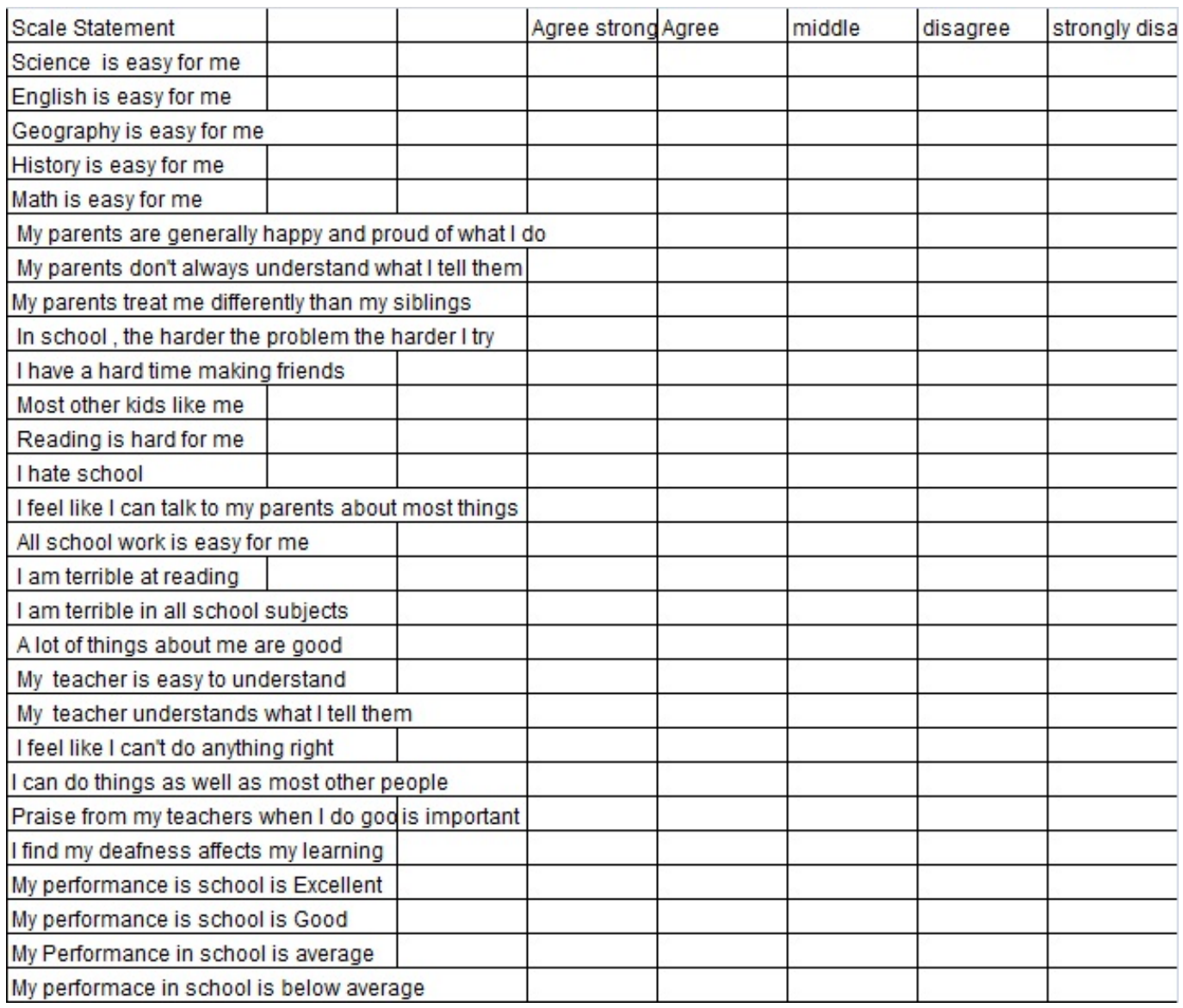

Teacher questionnaire 


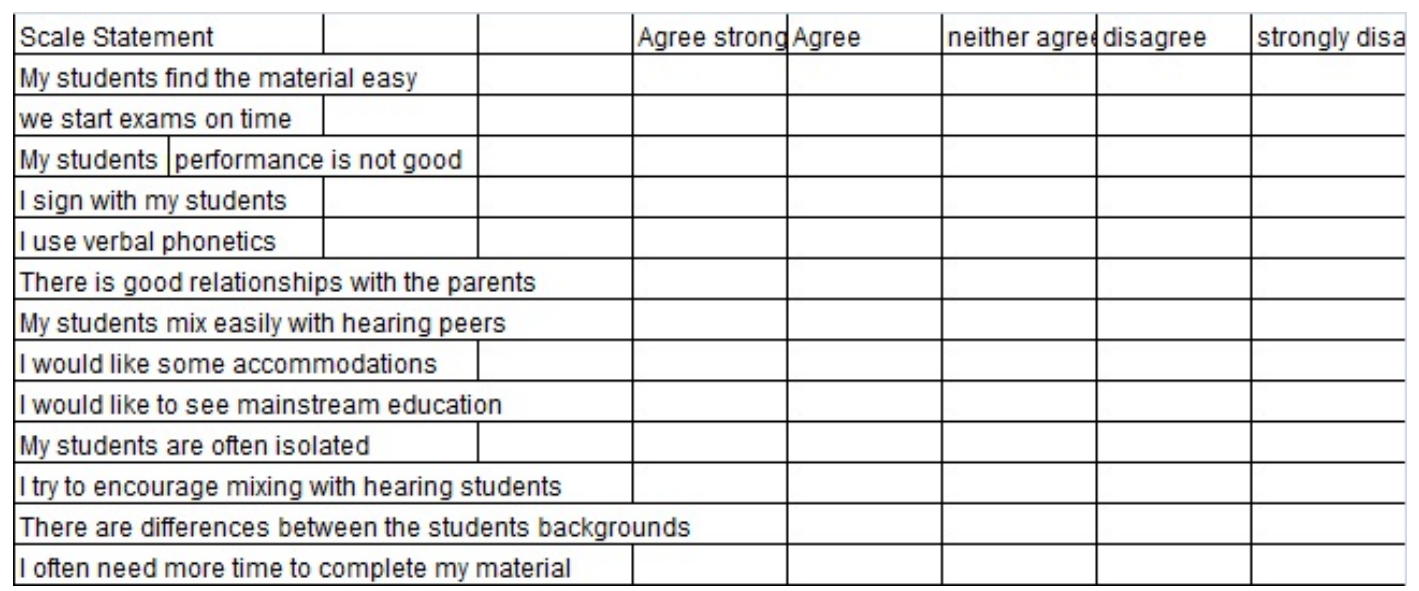

